\title{
Alcohol-Based Handrub Utilization Practice for COVID-19 Prevention Among Pharmacy Professionals in Ethiopian Public Hospitals: A Cross-Sectional Study
}

This article was published in the following Dove Press journal: Drug, Healthcare and Patient Safety

\author{
Assefa Mulu Baye (D) \\ Andualem Ababu (iD) ${ }^{2}$ \\ Regasa Bayisa ${ }^{2}$ \\ Mahdi Abdella ${ }^{2}$ \\ Edessa Diriba ${ }^{2}$ \\ Minychel Wale ${ }^{3}$ \\ Muluken Nigatu Selam (D) ${ }^{4}$ \\ 'Department of Pharmacology and \\ Clinical Pharmacy, School of Pharmacy, \\ Addis Ababa University, Addis Ababa, \\ Ethiopia; ${ }^{2}$ Pharmaceutical and Medical \\ Equipment Directorate (PMED), Ministry \\ of Health, Addis Ababa, Ethiopia; ${ }^{3} \mathrm{All}$ \\ African Leprosy, Tuberculosis \\ Rehabilitation and Training Center \\ (ALERT), Addis Ababa, Ethiopia; \\ ${ }^{4}$ Department of Pharmaceutics and Social \\ Pharmacy, School of Pharmacy, Addis \\ Ababa University, Addis Ababa, Ethiopia
}

Purpose: Rubbing the hands with alcohol-based handrub (ABHR) is globally recommended as the preferred approach to prevent healthcare-associated infections in most routine encounters with patients, except in cases handwashing with soap and water is advised. Inappropriate utilization of ABHR could have detrimental effects, most importantly during the coronavirus disease (COVID19) pandemic, which include exposure of healthcare professionals to healthcare-associated infections and the development of resistant microorganisms. In a hospital setting, the utilization of ABHR among frontline healthcare workers including pharmacy professionals is low. Therefore, the purpose of this study was to explore the current practice of hand rubbing among pharmacy professionals in public hospitals of Addis Ababa during the pandemic of COVID-19.

Methods: The study was a cross-sectional study using a self-reported questionnaire conducted among pharmacy professionals in public hospitals found in Addis Ababa from 10th May to 9th June, 2020 to recognize ABHR utilization rate. Data were collected on a sample of 384 pharmacy professional by a self-administered questionnaire. Data analysis was done using software for the statistical package for social science version 25.0. To identify the significant predictors of ABHR utilization practice bivariable and multivariable logistic regressions were carried out. Crude odds ratio and adjusted odds ratio with $95 \%$ confidence interval were calculated to determine the predictors.

Results: Out of 384 participants, three hundred and four participants were included in the final analyses after the exclusion of incomplete responses. Female participants represented $41.4 \%$ of the study participants. More than half (58.9\%) of the pharmacy professionals had sufficient knowledge on ABHR utilization for COVID-19 prevention. Similarly, 56.6\% of pharmacy professionals had positive attitude towards ABHR for COVID-19 prevention. But only $35.9 \%$ of the study participants had good ABHR utilization practice.

Conclusion: Despite the modest level of knowledge and attitude towards ABHR, pharmacy professionals' utilization practice of ABHR for COVID-19 prevention was found to be suboptimal. Provision of ABHR solutions through hospitals and increasing the awareness of pharmacy professionals on ABHR needs to be encouraged.

Keywords: ABHR, practice, pharmacy professionals, Addis Ababa

\section{Introduction}

Healthcare-associated infections (HCAIs) are critical public health challenges in many countries, that result in an increase in the morbidity and mortality of patients and healthcare providers including pharmacy professionals, and incur additional
Correspondence: Assefa Mulu Baye Pharmacy, School of Pharmacy, Addis Ababa University, P.O. Box II76, Addis Ababa, Ethiopia

Tel +25I 910980410

Email assefa.mulu@aau.edu.et
Drug, Healthcare and Patient Safety 2021:13 37-46 
costs in healthcare settings. In developing countries, the magnitude of the problem can exceed $25 \%$, attributing to morbidity and mortality. ${ }^{1-3}$

Rubbing the hands with ABHR is internationally recommended as the preferred method for hand hygiene in the usual encounters with patients, except in case of handwashing with soap and water is advised. ${ }^{4}$ ABHR has been recommended over handwashing with soap and water by the WHO because of its wide microbiological spectrum, time efficiency, availability at the point of care, and improved skin tolerance. ${ }^{5,6}$

Inappropriate utilization of ABHR could have detrimental effects, most importantly during the coronavirus disease (COVID-19) pandemic, which include wastage of resources, exposure of healthcare professionals to HCAIs, the development of resistant microorganisms and alcoholrelated fire hazards. ${ }^{7,8}$ Awareness of pharmacy professional on the appropriate utilization of ABHR can affect these undesirable consequences.

Pharmacy professionals are involved in the distribution of medications and may perceive that they have little contact with patients or clients in a hospital setting and could assume that they are not on the frontline or should not have to perform ABHR as much as physicians or nurses. Rather they are one of the front-line healthcare providers during COVID-19 pandemic; they provide public health services through patient care, regular supply of medicines, provision of health information on hand washing techniques, sanitizer preparation and utilization, availability of face masks and instructions for their proper use and disposal. ${ }^{9,10}$ Pharmacy professionals' hands may become contaminated when distributing medications to various wards, while in the elevators, opening doors, handdelivering special medications to a nurse or physician, while eating, touching any unclean surfaces. Therefore, pharmacists must perform hand hygiene as often as providers that have direct patient care to help prevent HCAIs.

Pharmacy professionals' knowledge about ABHR utilization in COVID-19 is important because it affects their ABHR utilization practice and contribution as a frontline healthcare cadre. ${ }^{11}$ A study in China indicated that the top three reported reasons that might prevent healthcare workers from using ABHR were feeling ABHR residual to be pleasant, ABHR irritated their skin; and splashing occurred when applying ABHR. ${ }^{12}$ Despite this, the literature seems to focus mainly on healthcare providers other than pharmacy professionals and the wider aspects of hand hygiene with less emphasis on investigating hand rubbing practices with ABHR among healthcare professionals.

Globally there was no recent extensive attention on investigating pharmacy professionals' utilization practices of hand rubbing using ABHR, particularly in the era of the COVID19 pandemic. More specifically, no Ethiopian study has investigated ABHR utilization practices among pharmacy professionals. This is despite the high burden of HCAIs, especially infections associated with multi-drug resistant organisms, and acceptable evidence that hand rubbing with ABHR contributes significantly to reducing these HCAIs. ${ }^{13,14}$

Hence, the purpose of this study was to explore the current practice of hand rubbing and associated factors among pharmacy professionals in public hospitals of Addis Ababa during the pandemic of COVID-19. The findings of this study will contribute to better understanding of ABHR utilization practice among pharmacy professionals in Ethiopia.

\section{Methods}

\section{Study Design and Setting}

The study was a cross-sectional study using a self-reported questionnaire conducted from 10th May to 9th June, 2020. The study was conducted in thirteen public hospitals of Addis Ababa, Ethiopia.

\section{Sample Size and Sampling Technique}

The required sample was calculated using single population proportion formula with the assumption of the proportion $\mathrm{P}$ of $50 \%$ (as there was no previous study), marginal error of 5\%, and a standard $Z$ score of 1.96 corresponding to $95 \%$ confidence interval. Hence, the calculation yielded a sample size of 384 pharmacy professionals. An equal proportion of the sample was allocated to the public hospitals in Addis Ababa. Finally, consecutive sampling was applied until all the available pharmacy professionals were included in the study.

\section{Eligibility Criteria Inclusion Criteria}

All pharmacy professionals who had been working for more than 6 months in public hospitals were included in this study.

\section{Exclusion Criteria}

Pharmacy professionals who were not willing to participate were excluded from the study. 


\section{Data Collection}

Data collection was done by a self-administered questionnaire adapted from the literature review. ${ }^{4,15,16}$ The data collection tool consisted of questions related to sociodemographic, knowledge, attitude, and practice on ABHR. A two-day training was provided to the data collectors. The training focused on the purpose of the study, data collection tools, ethical considerations, ways of obtaining the verbal consent and how to interact with respondents. The data collectors were two pharmacy professionals under the supervision of two field supervisors. Data were collected from the study participants while they were not on duty.

\section{Data Analysis}

Data analysis was done using software for the statistical package for social science (SPSS) version 25.0. Before further data analysis, reverse scoring for negatively worded items was checked. The socio-demographic characteristics of respondents were analyzed with descriptive analysis. To identify the significant predictors of ABHR utilization practice bivariable and multivariable logistic regressions were carried out. To determine the predictors of ABHR practice, crude odds ratio (COR), and adjusted odds ratio (AOR) with 95\% CI were computed and P-value less 0.05 was considered to declare statistical significance.

Correct answers for knowledge of pharmacy professionals on ABHR were assigned 1 point, whereas incorrect answers were assigned 0 points. The total score for the knowledge items ranged from 0 to 11, with a higher score indicating a better knowledge of ABHR for COVID-19 prevention. The score of the participants was further divided into two categories on the basis of the mean value. Scores above the mean value were characterized as "sufficient knowledge" and less than the mean value were labelled as "insufficient knowledge".

The statements to assess attitude of pharmacy professionals towards ABHR for COVID-19 prevention were consisting of responses with a 5-point Likert scale (from "strongly disagree" to "strongly agree") options. The overall score in this section would have a possible range of 9 to 45. The score of the participants was further divided into two categories on the basis of the median value. Scores greater than the median value indicated "positive attitude" and less than or equal to the median indicated "negative attitude" on ABHR utilization for COVID-19.
There were 5 statements consisting of responses with "yes" or "no" to assess ABHR utilization practice. Good ABHR utilization practice was assigned when all of the practice items are performed appropriately.

\section{Ethics}

The ethical Review Committee of the School of Pharmacy, Addis Ababa University granted the ethical approval for this study (ERB/SOP/214/06/2020). Verbal consent was obtained from pharmacy professionals before data collection. Participation in the study was voluntary. The study participants were informed about the purpose of the study, and verbal informed consent was approved by the ethical review committee. The data collected from the pharmacy professionals were kept confidential and maintained locked throughout the study. The data were recorded in paper forms and only the principal investigators had access to the data. The study was conducted in accordance with the Declaration of Helsinki.

\section{Result}

Out of 384 participants, 355 responded for the questionnaire (response rate $=92.5 \%$ ). Three hundred and four participants were included in the final analyses after the exclusion of incomplete responses. Female participants represented $41.4 \%$ (126) of the study participants. The age of participants ranged from 22 to 55 years, with a mean age of 31.6 years (SD 6.11). In total, only $21.4 \%$ (65) of participants acknowledged that they received training in ABHR preparation and utilization after the emergence of COVID-19 (Table 1).

\section{Knowledge of Pharmacy Professionals About ABHR}

Table 2 presents the details of knowledge of pharmacy professionals about ABHR utilization for COVID-19. Among the hand hygiene methods, only 18 participants (5.9\%) indicated that both hand washing and ABHR are equally effective. The majority of study subjects $(80.9 \%)$ identified that the effective concentration of alcohol in ABHR solution to be 75 to $85 \%$. Fifty-five study participants $(18.1 \%)$ reported that ABHR solution needs to be diluted with water prior to use.

For the knowledge items, correct answers were assigned 1 point, whereas incorrect answers were assigned 0 points. The total score of the participants was further categorized into two categories with a cut-off value (on the 
Table I Sociodemographic Characteristics of Pharmacy Professionals in Public Hospitals, Addis Ababa, 2020

\begin{tabular}{|c|c|c|c|}
\hline \multicolumn{2}{|l|}{ Characteristics } & Frequency & Percent \\
\hline \multirow[t]{5}{*}{ Age, years } & Mean $( \pm S D)$ & \multicolumn{2}{|c|}{$31.6( \pm 6.11)$} \\
\hline & $\leq 25$ & 26 & 8.6 \\
\hline & $26-35$ & 221 & 72.7 \\
\hline & $36-45$ & 44 & 14.5 \\
\hline & $46-55$ & 13 & 4.3 \\
\hline \multirow[t]{2}{*}{ Sex } & Male & 178 & 58.6 \\
\hline & Female & 126 & $4 I .4$ \\
\hline \multirow[t]{5}{*}{ Religion } & Orthodox & 184 & 60.5 \\
\hline & Protestant & 60 & 19.7 \\
\hline & Muslim & 44 & 14.5 \\
\hline & Catholic & 5 & 1.6 \\
\hline & Other* & 11 & 3.6 \\
\hline \multirow[t]{4}{*}{ Marital Status } & Never married & 133 & 43.8 \\
\hline & Married & 136 & 44.7 \\
\hline & $\begin{array}{l}\text { Living with } \\
\text { partner }\end{array}$ & 24 & 7.9 \\
\hline & $\begin{array}{l}\text { Divorced/ } \\
\text { separated }\end{array}$ & 11 & 3.6 \\
\hline \multirow[t]{3}{*}{ Qualification } & Diploma & 25 & 8.2 \\
\hline & First degree & 232 & 76.3 \\
\hline & Second degree & 47 & 15.5 \\
\hline \multirow[t]{3}{*}{ Leadership } & $\begin{array}{l}\text { No leadership } \\
\text { position }\end{array}$ & 228 & 75.0 \\
\hline & $\begin{array}{l}\text { Case team } \\
\text { leader }\end{array}$ & 67 & 22.0 \\
\hline & Director & 9 & 3.0 \\
\hline \multirow[t]{3}{*}{ Work experiences } & Mean $( \pm S D)$ & \multicolumn{2}{|c|}{$6.5( \pm 5.26)$} \\
\hline & $\leq 5$ years & 156 & 51.3 \\
\hline & $>5$ years & 148 & 48.7 \\
\hline \multirow[t]{2}{*}{ Training on $A B H R$} & Yes & 65 & 21.4 \\
\hline & No & 239 & 78.6 \\
\hline \multirow[t]{3}{*}{ Source of $A B H R$} & Hospital & 253 & 83.2 \\
\hline & Purchased & 28 & 9.2 \\
\hline & Both & 23 & 7.6 \\
\hline \multirow{2}{*}{$\begin{array}{l}\text { Availability of wall- } \\
\text { mounted } A B H R\end{array}$} & Yes & 208 & 68.4 \\
\hline & No & 96 & 31.6 \\
\hline
\end{tabular}

Note: *Waqafetaa, 7th Day Adventist, Johba.

Abbreviations: ABHR, alcohol-based handrub; ENT, ear, nose and throat; OPD, outpatient pharmacy; SD, standard deviation.

basis of the mean value) of $7.65(70 \%)$. The scores of $\geq 7.65$ were characterized as "sufficient knowledge" and $<7.65$ were labelled as "insufficient knowledge". As a result, 179 (58.9\%) pharmacy professionals had sufficient knowledge on ABHR utilization for COVID-19 prevention.

\section{Attitude Towards ABHR Utilization for COVID-19}

Table 3 presents the details of attitude towards ABHR utilization for COVID-19. One-fourth of the respondents believed that the costs of ABHR outweigh the benefits. Less than $19 \%$ of the pharmacy professionals perceived that the gel form of ABHR product is more preferable than the solution.

The items assessing the attitude were consisting of responses with a 5-point Likert scale (from "strongly disagree" to "strongly agree") options. The overall score of participants in this section was in the range of 14 to 45 . The score of the participants was further divided into two categories with a cutoff value (on the basis of the median value) of 32 (71.1\%). Therefore, $172(56.6 \%)$ pharmacy professionals had positive attitude towards ABHR for COVID-19 prevention.

\section{ABHR Utilization Practice to Prevent COVID-19}

As indicated in Table 4, more than three-fourth of the participants $(78.9 \%)$ claimed that they routinely use ABHR for hand hygiene. Similarly, $76.0 \%$ of the pharmacy professionals reported that they do not apply protective cream immediately after the use of ABHR on hands. Among the 304 study participants, majority, 278 (91.4\%) claimed that they use ABHR after touching patients' surroundings and/or patients' items.

Among the 5 statements to assess the practice consisting of responses with "yes" or "no", good ABHR practice was assigned when all of the practice items are performed appropriately. Among the 304 pharmacy professionals only one-third, $109(35.9 \%)$, had good practice on the utilization of ABHR for COVID-19 prevention whereas the rest $195(64.1 \%)$ were having poor practice.

\section{Factor Affecting ABHR Utilization}

Crude odds ratio and adjusted odds ratio (AOR) were computed to determine the predictors of ABHR utilization by pharmacy professionals (Table 5). Variables including age, sex, qualification, leadership position, experience on current position, training on ABHR, availability of wallmounted ABHR and attitude towards ABHR were not found to be associated with ABHR utilization practice. On the other hand, source of ABHR and knowledge on ABHR were found to be determinants of ABHR utilization 
Table 2 Knowledge of Pharmacy Professionals on ABHR Utilization for COVID-19, Addis Ababa, 2020

\begin{tabular}{|c|c|c|c|}
\hline \multicolumn{2}{|l|}{ Knowledge Items } & \multirow{4}{*}{$\begin{array}{r}\text { Frequency } \\
143 \\
143\end{array}$} & \multirow{4}{*}{$\begin{array}{r}\text { Percent } \\
47.0 \\
47.1 \\
\\
5.9\end{array}$} \\
\hline Which hand hygiene method is more effective in killing bacteria? & ABHR & & \\
\hline & $\begin{array}{l}\text { Hand washing with soap and } \\
\text { water }\end{array}$ & & \\
\hline & Both are equally effective & & \\
\hline \multirow{3}{*}{$\begin{array}{l}\text { What is the effective concentration of alcohol in WHO-recommended ABHR } \\
\text { solution? }\end{array}$} & $<60 \%$ & 6 & 2.0 \\
\hline & $>95 \%$ & 52 & 17.1 \\
\hline & $75-85 \%$ & 246 & 80.9 \\
\hline \multirow[t]{2}{*}{ When hands are visibly dirty, can ABHR alone be used for hand hygiene? } & Yes & 57 & 18.8 \\
\hline & No & 247 & 81.3 \\
\hline \multirow{2}{*}{$\begin{array}{l}\text { When hands are contaminated with blood, can ABHR alone be used for hand } \\
\text { hygiene? }\end{array}$} & Yes & 52 & 17.1 \\
\hline & No & 252 & 82.9 \\
\hline \multirow{2}{*}{$\begin{array}{l}\text { Does ABHR have good antimicrobial activity against bacteria, viruses, fungi, and } \\
\text { bacterial spore? }\end{array}$} & Yes & 233 & 76.6 \\
\hline & No & 71 & 23.4 \\
\hline \multirow[t]{2}{*}{ Can ABHR be used for mucosal surface disinfection? } & Yes & 82 & 27.0 \\
\hline & No & 222 & 73.0 \\
\hline \multirow[t]{3}{*}{ How long should you rub your hands together after applying ABHR? } & $15-20$ seconds & 89 & 29.3 \\
\hline & $20-30$ seconds & 201 & 66.1 \\
\hline & $30-60$ seconds & 14 & 4.6 \\
\hline \multirow[t]{5}{*}{ How much is the minimum amount of $A B H R$ required on an average for single use? } & $\mathrm{I} \mathrm{mL}$ & 33 & 10.9 \\
\hline & $2 \mathrm{~mL}$ & 156 & 51.3 \\
\hline & $3 \mathrm{~mL}$ & 64 & 21.1 \\
\hline & $5 \mathrm{~mL}$ & 47 & 15.5 \\
\hline & $10 \mathrm{~mL}$ & 4 & 1.3 \\
\hline \multirow[t]{4}{*}{ How many steps are in involved in application of $A B H R$ ? } & I step & 8 & 2.6 \\
\hline & 2 steps & 85 & 28.0 \\
\hline & 6 steps & 162 & 53.3 \\
\hline & II steps & 49 & 16.1 \\
\hline \multirow[t]{2}{*}{ ABHR solution needs to be diluted with water prior to use. } & Yes & 55 & 18.1 \\
\hline & No & 249 & 81.9 \\
\hline \multirow[t]{3}{*}{ For which population is ABHR recommended for? } & Adults only & 90 & 29.6 \\
\hline & Children only & 7 & 2.3 \\
\hline & Both & 207 & 68.1 \\
\hline
\end{tabular}

Note: Bold, correct answers.

Abbreviation: ABHR, alcohol-based handrub.

practice. Those study participants getting ABHR from the hospitals had more than three times good ABHR utilization practice compared to those who obtain from all sources (AOR, 3.34; 95\% CI, 1.06-10.50; P-value, 0.039). Pharmacy professionals with sufficient knowledge on ABHR had more than twice good ABHR utilization practice as compared to those with insufficient knowledge (AOR, 2.33; 95\% CI, 1.36-4.00; P-value, 0.002).

\section{Discussion}

This was the first survey of its kind to assess ABHR utilization practice of pharmacy professionals in public hospitals of Addis Ababa, Ethiopia. Among 384 samples of pharmacy professionals, 304 were included for final analysis. At the time of COVID-19 pandemic healthcare providers were in haste with limited time to respond for questionnaires. 
Table 3 Attitude of Pharmacy Professionals Towards ABHR Utilization for COVID-19 in Public Hospitals, Addis Ababa, 2020

\begin{tabular}{|c|c|c|c|c|c|}
\hline \multirow[t]{2}{*}{ Attitude Items } & \multicolumn{5}{|c|}{ Response, n (\%) } \\
\hline & $\begin{array}{l}\text { Strongly } \\
\text { Disagree }\end{array}$ & Disagree & Neutral & Agree & $\begin{array}{l}\text { Strongly } \\
\text { Agree }\end{array}$ \\
\hline $\begin{array}{l}\text { Using ABHR has positive impact on infection preventive and } \\
\text { control program }\end{array}$ & $23(7.6)$ & $37(12.2)$ & $87(28.6)$ & $109(35.9)$ & $48(15.8)$ \\
\hline The costs of alcohol-based handrubs outweigh the benefits & $77(25.3)$ & $58(19.1)$ & $60(19.7)$ & $50(16.4)$ & $59(19.4)$ \\
\hline $\begin{array}{l}\text { I am not expected to use } A B H R \text { in my practice setting when } \\
\text { handwashing is not feasible }\end{array}$ & $149(49.0)$ & $75(24.7)$ & $37(12.2)$ & $28(9.2)$ & $15(4.9)$ \\
\hline Use of $A B H R$ may make my hands drier and cause skin damage & $57(18.8)$ & $91(29.9)$ & $85(28.0)$ & $47(15.5)$ & $24(7.9)$ \\
\hline I do not feel that my hands are clean after using $A B H R$ & $66(21.7)$ & $127(4 \mid .8)$ & $40(13.2)$ & $52(17.1)$ & $19(6.3)$ \\
\hline $\begin{array}{l}\text { My religious and cultural beliefs prevent me from using } A B H R \text { in } \\
\text { my healthcare setting }\end{array}$ & $176(57.9)$ & $52(17.1)$ & $26(8.6)$ & $27(8.9)$ & $23(7.6)$ \\
\hline I find $A B H R$ unpleasant to use & $85(28.0)$ & $91(29.9)$ & 7I (23.4) & $35(11.5)$ & $22(7.2)$ \\
\hline $\mathrm{ABHR}$ is cumbersome and inconvenient & $82(27.0)$ & $106(34.9)$ & $55(18.1)$ & $47(15.5)$ & $14(4.6)$ \\
\hline $\begin{array}{l}\text { The gel form of } A B H R \text { product is more preferable than the } \\
\text { solution? }\end{array}$ & $44(14.5)$ & $43(14.1)$ & $86(28.3)$ & $74(24.3)$ & $57(18.8)$ \\
\hline
\end{tabular}

Abbreviations: ABHR, alcohol-based handrub; HIV, human immunodeficiency virus; TB, tuberculosis.

In our survey, $68.4 \%$ of the respondents reported that they had wall-mounted dispenser for ABHR. Hand hygiene experts recommend placing ABHR in convenient locations that are consistent with staff workflow patterns. ${ }^{17}$

Table 4 ABHR Utilization Practice of Pharmacy Professionals in Public Hospitals, Addis Ababa, 2020

\begin{tabular}{|l|l|l|}
\hline \multirow{2}{*}{ Practice Items } & \multicolumn{2}{c|}{$\begin{array}{c}\text { Response, } \\
\text { n (\%) }\end{array}$} \\
\cline { 2 - 4 } & Yes & No \\
\hline Do you routinely use ABHR for hand hygiene? & $\begin{array}{l}240 \\
(78.9)\end{array}$ & $\begin{array}{l}64 \\
(21.1)\end{array}$ \\
\hline $\begin{array}{l}\text { I adhere to correct ABHR HH practices at all } \\
\text { times }\end{array}$ & $\begin{array}{l}208 \\
(68.4)\end{array}$ & $\begin{array}{l}96 \\
(31.6)\end{array}$ \\
\hline $\begin{array}{l}\text { I do not apply protective cream (emollient or } \\
\text { moisturizer) immediately after use of ABHRs on } \\
\text { hands? }\end{array}$ & $\begin{array}{l}231 \\
(76.0)\end{array}$ & $\begin{array}{l}73 \\
(24.0)\end{array}$ \\
\hline $\begin{array}{l}\text { When using an ABHR to decontaminate hands, do } \\
\text { you rub together until dry? }\end{array}$ & $\begin{array}{l}240 \\
(78.9)\end{array}$ & $\begin{array}{l}64 \\
(21.1)\end{array}$ \\
\hline $\begin{array}{l}\text { I use ABHR after touching patient surroundings } \\
\text { and/or their properties }\end{array}$ & $\begin{array}{l}278 \\
(91.4)\end{array}$ & $\begin{array}{l}26 \\
(8.6)\end{array}$ \\
\hline
\end{tabular}

Abbreviation: ABHR, alcohol-based handrub; $\mathrm{HH}$, hand hygiene.
Hand hygiene utilization can be influenced by visibility and accessibility of ABHR dispensers. ${ }^{18}$

Even in the time of COVID-19 epidemic, training on ABHR was not adequately provided for pharmacy professionals. Among the study participants, only 65 pharmacy professionals (21.4\%) took training on ABHR production and utilization. This was lower as compared to a study in Mari General Hospital, Nigeria, where thirty-three (44\%) respondents had received formal training in hand hygiene that encompasses hand rubbing with alcohol. ${ }^{19}$

ABHR has been recommended over handwashing with soap and water by the WHO because of its wide microbiological spectrum, time efficiency, availability at the point of care, and improved skin tolerance. ${ }^{5,6}$ In the current study, less than half $(47 \%)$ of the respondents knew that ABHR is more effective in killing bacteria than washing hands with soap and water. Two-third, $66.1 \%$ of pharmacy professionals knew that $20-30$ seconds is the recommended time required for effective hand hygiene with ABHR solution as documented in the WHO guideline. ${ }^{5}$ The finding was higher as compared to a study in Sri Lanka in which only few medical and nursing students (35\% and $25 \%$, respectively) knew that 20 seconds is the minimum time required for effective hand hygiene. ${ }^{20}$ Likewise, in an Indian study, only one- 
Table 5 Determinants of ABHR Utilization Practice Among Pharmacy Professionals in Public Hospitals, Addis Ababa, 2020

\begin{tabular}{|c|c|c|c|c|c|}
\hline \multicolumn{2}{|c|}{ Variables } & \multicolumn{2}{|c|}{ Practice } & \multirow[t]{2}{*}{ COR (\%95 Cl) } & \multirow{2}{*}{ AOR $(95 \% \mathrm{Cl})$} \\
\hline & & Good (\%) & Poor (\%) & & \\
\hline Age & $\begin{array}{l}\leq 25 \text { years } \\
26-35 \text { years } \\
36-45 \text { years } \\
46-55 \text { years }\end{array}$ & $\begin{array}{l}\text { II (42.3) } \\
79(35.7) \\
\text { I7 (38.6) } \\
2(15.4)\end{array}$ & $\begin{array}{l}\text { I5 (57.7) } \\
\text { I42(64.3) } \\
27(6 \mathrm{I} .4) \\
\text { II (84.6) }\end{array}$ & $\begin{array}{l}4.03(0.74-21.98) \\
3.06(0.66-14.15) \\
3.46(0.68-17.57) \\
1.00\end{array}$ & $\begin{array}{l}4.89(0.78-30.50) \\
3.52(0.7 I-17.39) \\
4.20(0.80-22.06) \\
1.00\end{array}$ \\
\hline Sex & $\begin{array}{l}\text { Female } \\
\text { Male }\end{array}$ & $\begin{array}{l}46(36.5) \\
63(35.4)\end{array}$ & $\begin{array}{l}80(63.1) \\
115(64.6)\end{array}$ & $\begin{array}{l}1.05(0.65-1.69) \\
1.00\end{array}$ & $\begin{array}{l}1.08(0.64-1.83) \\
1.00\end{array}$ \\
\hline Qualification & $\begin{array}{l}\text { Diploma } \\
\text { First degree } \\
\text { Second degree }\end{array}$ & $\begin{array}{l}7(28.0) \\
79(34.1) \\
23(48.9)\end{array}$ & $\begin{array}{l}18(72.0) \\
153(65.9) \\
24(51.1)\end{array}$ & $\begin{array}{l}0.41(0.14-1.15) \\
0.54(0.29-1.02) \\
1.00\end{array}$ & $\begin{array}{l}0.53(0.17-1.63) \\
0.51(0.25-1.03) \\
1.00\end{array}$ \\
\hline Leadership & $\begin{array}{l}\text { No leadership position } \\
\text { Director } \\
\text { Case team leader }\end{array}$ & $\begin{array}{l}83(36.4) \\
3(33.3) \\
23(34.3)\end{array}$ & $\begin{array}{l}145(63.6) \\
6(66.7) \\
44(65.7)\end{array}$ & $\begin{array}{l}1.10(0.62-1.94) \\
0.96(0.22-4.18) \\
1.00\end{array}$ & $\begin{array}{l}I .41(0.75-2.66) \\
0.87(0.19-4.08) \\
1.00\end{array}$ \\
\hline Experience & $\begin{array}{l}\leq 5 \text { years } \\
>5 \text { years }\end{array}$ & $\begin{array}{l}57(36.5) \\
52(35.1)\end{array}$ & $\begin{array}{l}99(63.5) \\
96(64.9)\end{array}$ & $\begin{array}{l}\text { I.06 (0.67-I.70) } \\
1.00\end{array}$ & $\begin{array}{l}0.94(0.54-1.65) \\
1.00\end{array}$ \\
\hline Training on $A B H R$ & $\begin{array}{l}\text { Yes } \\
\text { No }\end{array}$ & $\begin{array}{l}22(33.8) \\
87(36.4)\end{array}$ & $\begin{array}{l}43(66.2) \\
152(63.6)\end{array}$ & $\begin{array}{l}0.89(0.50-1.59) \\
1.00\end{array}$ & $\begin{array}{l}0.98(0.52-1.85) \\
1.00\end{array}$ \\
\hline Source of $A B H R$ & $\begin{array}{l}\text { Hospital } \\
\text { Purchased } \\
\text { All sources }\end{array}$ & $\begin{array}{l}97(38.3) \\
8(28.4) \\
4(17.4)\end{array}$ & $\begin{array}{l}156(61.7) \\
20(71.4) \\
19(82.6)\end{array}$ & $\begin{array}{l}2.95(0.98-8.94) \\
1.90(0.49-7.36) \\
1.00\end{array}$ & $\begin{array}{l}3.34(1.06-10.50)^{*} \\
2.14(0.52-8.85) \\
1.00\end{array}$ \\
\hline Availability of wall mounted $A B H R$ & $\begin{array}{l}\text { Yes } \\
\text { No }\end{array}$ & $\begin{array}{l}72(34.6) \\
37(38.5)\end{array}$ & $\begin{array}{l}136(65.4) \\
59(61.5)\end{array}$ & $\begin{array}{l}0.84(0.51-1.39) \\
1.00\end{array}$ & $\begin{array}{l}0.70(0.40-1.21) \\
1.00\end{array}$ \\
\hline Knowledge on $A B H R$ & $\begin{array}{l}\text { Sufficient } \\
\text { Insufficiency }\end{array}$ & $\begin{array}{l}78(43.6) \\
31(24.8)\end{array}$ & $\begin{array}{l}\text { I0I (56.4) } \\
94(75.2)\end{array}$ & $\begin{array}{l}2.34(1.42-3.87)^{*} \\
1.00\end{array}$ & $\begin{array}{l}2.33(1.36-4.00)^{*} \\
1.00\end{array}$ \\
\hline Attitude towards $\mathrm{ABHR}$ & $\begin{array}{l}\text { Positive } \\
\text { Negative }\end{array}$ & $\begin{array}{l}67(39.0) \\
42(31.8)\end{array}$ & $\begin{array}{l}105(61.0) \\
90(68.2)\end{array}$ & $\begin{array}{l}1.37(0.85-2.20) \\
1.00\end{array}$ & $\begin{array}{l}\text { I.16 (0.69-1.94) } \\
\text { I:00 }\end{array}$ \\
\hline
\end{tabular}

Note: *P-value $<0.05$.

Abbreviations: $\mathrm{ABHR}$, alcohol-based handrub; $\mathrm{AOR}$, adjusted odds ratio; $\mathrm{Cl}$, confidence interval; $\mathrm{COR}$, crude odds ratio.

third of health science students knew the duration required for a hand sanitizer to kill the microbials on the hands. ${ }^{21}$ On-job experience and an increased awareness related to COVID-19 epidemic may account for the variation.

In the knowledge section of the questionnaire, the minimum knowledge score achieved was 3 and the maximum was 11 , with a mean of $7.6(\mathrm{SD} \pm 1.60)$. Overall, according to the criteria of scoring (a mean score of $70 \%), 179$ (58.9\%) pharmacy professionals had sufficient knowledge on ABHR utilization for COVID-19 prevention. Our finding was lower than the result in Saudi primary care centers where the majority of respondents (83.0\%) had good knowledge of hand hygiene. The general evaluation of knowledge on hand hygiene in the later study may justify the difference as ours is specifically on ABHR utilization for COVID-19 prevention.

In the current study, only one-third of pharmacy professionals agreed that the costs of ABHR solutions outweigh the benefits. In a study in China, the majority of ABHR utilizers stated that they would not be willing to pay the actual cost of the ABHR. ${ }^{12}$ The difference could be our study was conducted at the time of COVID-19 pandemic that escalates the demand for sanitizers to prevent the acquisition of the pandemic.

Nearly one-fourth of study participants agreed that the use of ABHR may make their hands drier and cause skin damage. In the Chinese study, the top three reported reasons that might prevent healthcare workers from using 
ABHR were feeling ABHR residual to be pleasant, ABHR irritated their skin; and splashing occurred when applying ABHR. $^{12}$

In our study, one-third of pharmacy professionals agreed towards the preference of the gel form of ABHR product than ABHR solution. By the study in medical intensive care unit (ICU) of the University of Geneva Hospital, based on self-assessment, observer assessment, and the measurement of epidermal water content, the gel performed significantly better than the liquid formulation. Forty-seven healthcare providers $(57 \%)$ rated the gel as better than the liquid formulation, $13(16 \%)$ as equivalent to the liquid formulation, whereas $22(27 \%)$ considered the gel formulation to be inferior. ${ }^{22}$ In a study that compared gel formulation of alcohol with the traditional handcleansing agents, it was demonstrated that alcohol gel was as effective as $70 \%$ ethyl alcohol in removing clinical strains of $A$. baumannii, methicillin-resistant $S$. aureus, E. coli, E. faecalis, P. aeruginosa, and C. albicans from heavily contaminated hands of human volunteers. ${ }^{23}$ The lower concentration of ethyl alcohol used for comparison might be the reason for the equivalence in the efficacy of the gel and the liquid solution.

Based on a median score of $71.1 \%$ to dichotomize study participants as positive and negative attitude towards ABHR, more than half (56.6\%) of pharmacy professionals had positive attitude towards ABHR for COVID-19 prevention. Similarly, there was an overall positive attitude from study participants toward hand hygiene practice in a study conducted in Saudi Arabia. ${ }^{16}$

Although attitude to hand rubbing using ABHR was predominately positive, sub-optimal practices were reported in the study participants of this study. Despite clear and unambiguous recommendations in the World Health Organization ${ }^{4}$ and national guidelines ${ }^{24}$ regarding when to handrub using ABHR confusion among pharmacy professionals persists.

Given this lack of awareness among pharmacy professionals on the minimum amount of ABHR required for a single application (48.7\%), steps of ABHR application (46.7\%) and the comparative efficacy of ABHR and handwashing with soap and water, it is unsurprising therefore to find that $21.1 \%$ of pharmacy professionals were not hand rubbing with ABHR almost all of the time. Despite this finding, $91.4 \%$ of study participants reported that they use ABHR after touching patient surroundings and/or their properties as recommended by guidelines. However, these results are interpreted taking into account that study participants may self-report a high rate of personal compliance ${ }^{25}$ and that hand hygiene beliefs, knowledge and practices do not always correlate. ${ }^{26,27}$ This was similar to a study in Saudi Arabia where $81.9 \%$ of health professionals acknowledged that they routinely make use of ABHR. ${ }^{16}$ We found that only onethird of the study participants had good practice on the utilization of ABHR for COVID-19 prevention. In the present study, ABHR utilization practice was declared to be good when all of the practice items are performed appropriately.

Healthcare providers' practice on hand hygiene was thought to be affected by various variables related to the contexts of the environment, social and the actual and potential risk of cross-transmission and to a positive individual attitude toward hand hygiene and infection prevention. ${ }^{28}$ This is particularly true in the current pandemic of COVID-19 in Ethiopia at the national level and the world at large, where healthcare professionals need to be cautious to strict infection preventive measures such as hand hygiene practice. In this study, pharmacy professionals that obtain ABHR solutions in public hospitals were found to have better utilization practice of ABHR. It is claimed that the quality of ABHR produced in public hospitals is preferred over the commercial one. In addition, when this study was conducted, hospitals were providing ABHR for healthcare providers for free. There was no correlation between ABHR utilization practice and participants' age, gender, years of work experience and leadership position. This is similar with a study conducted in Saudi Arabia on healthcare providers' practice of hand hygiene ${ }^{16}$ but training on ABHR was not found to be associated with ABHR utilization in our study. In addition to in-service trainings, informal sources of information regarding ABHR during the epidemics of COVID-19 may contribute for the awareness of pharmacy professional regarding ABHR.

Pharmacy professionals with sufficient knowledge of ABHR were found to have better ABHR utilization practice in public hospitals of Addis Ababa. Similarly, there was a significant correlation between the level of handrub practice with alcohol and higher score of knowledge $(\mathrm{p}<0.01)$ in the Saudi study. ${ }^{16}$

\section{Limitation}

The study is a novel multiple site study that explored ABHR utilization practice of pharmacy professionals and determinant factors. This is a questionnaire-based study 
and one major limitation is that we have not directly observed the actual ABHR utilization practice that participants may over-stated compliance rate. The haste and anxious environment associated with COVID-19 pandemic could affect the responses of study participants.

\section{Conclusion}

In the present study, we have explored that level of awareness regarding the ABHR solution is sufficient in $58.9 \%$ of pharmacy professionals in public hospitals of Addis Ababa. Likewise, 56.6\% of pharmacy professionals had positive attitude towards ABHR for COVID-19 prevention. Despite the modest level of knowledge and attitude towards ABHR, pharmacy professional utilization practice of ABHR for COVID-19 prevention was found to be low (35.9\%). Source of ABHR solution and knowledge on ABHR for COVID19 prevention were the determinant factors for ABHR utilization practice among pharmacy professionals in public hospitals. Providing of ABHR solutions through hospitals to healthcare providers and increasing the awareness of pharmacy professionals on the importance of ABHR utilization should be encouraged.

\section{Abbreviations}

ABHR, alcohol-based handrub; COVID-19, coronavirus disease 19; HCAI, healthcare-associated infection.

\section{Data-Sharing Statement}

All data are included within the manuscript. All data generated or analyzed during this study are included in the manuscript.

\section{Acknowledgment}

The authors would like to thank pharmacy professionals of the hospitals who participated in this study.

\section{Author Contributions}

All authors made a significant contribution to the work reported, whether that is in the conception, study design, execution, acquisition of data, analysis and interpretation, or in all these areas; took part in drafting, revising or critically reviewing the article; gave final approval of the version to be published; have agreed on the journal to which the article has been submitted; and agree to be accountable for all aspects of the work.

\section{Funding}

This study was supported by the Ministry of Health, Ethiopia.

\section{Disclosure}

The authors declare that they have no conflicts of interest for this work.

\section{References}

1. Mauldin PD, Salgado CD, Hansen IS, Durup DT, Bosso JA. Attributable hospital cost and length of stay associated with health care-associated infections caused by antibiotic-resistant gram-negative bacteria. Antimicrob Agents Chemother. 2010;54 (1):109-115. doi:10.1128/AAC.01041-09

2. Defez C, Fabbro-Peray P, Cazaban M, Boudemaghe T, Sotto A, Daurès J. Additional direct medical costs of nosocomial infections: an estimation from a cohort of patients in a French university hospital. J Hosp Infect. 2008;68(2):130-136. doi:10.1016/j.jhin.2007.11.005

3. Llata E, Gaynes RP, Fridkin S, Weinstein RA. Measuring the scope and magnitude of hospital-associated infection in the United States: the value of prevalence surveys. Clin Infect Dis. 2009;48 (10):1434-1440. doi:10.1086/598328

4. World Health Organization. Guide to local production: WHO-recommended handrub formulations. 2010. 2011.

5. Kilpatrick C, Allegranzi B, Pittet D. WHO first global patient safety challenge: clean care is safer care. Contributing to the training of health-care workers around the globe. Int J Infect Control. 2011;7 (2):17. doi:10.3396/ijic.V7i2.011.11

6. Pittet D, Hugonnet S, Harbarth S, et al. Effectiveness of a hospital-wide programme to improve compliance with hand hygiene. Infection control programme. Lancet. 2000;356(9238):1307-1312. doi:10.1016/S0140-6736(00)02814-2

7. Pittet D, Peters A, Tartari E. Enterococcus faecium tolerance to isopropanol: from good science to misinformation. Lancet Infect Dis. 2018;18(10):1065-1066. doi:10.1016/S1473-3099(18)30542-5

8. Selam MN, Bayisa R, Ababu A, et al. Increased production of alcohol-based hand rub solution in response to COVID-19 and fire hazard potential: preparedness of public hospitals in Addis Ababa, Ethiopia. Risk Manag Healthc Policy. 2020;13:2507. doi:10.2147/RMHP.S279957

9. Rutter V, Chan AHY, Tuck C, Bader L, Bates I. Weaving the health and pharmaceutical care agenda through the themes of the commonwealth heads of government meeting (CHOGM), London 2018. BioMed Central. 2018.

10. Bukhari N, Rasheed H, Nayyer B, Babar Z-U-D. Pharmacists at the Frontline Beating the COVID-19 Pandemic. Springer; 2020.

11. Pharmaceutical Group of European Union. Press Release Community pharmacists in the frontline in the fight against the novel corona-virus disease (COVID-19). Available on: https://www. pgeu.eu/publications/press-release-community-pharmacists-in-thefrontline-in-the-fight-against-the-novel-corona-virus-disease-covid19/. Accessed June 12, 2020.

12. Li Y, Wang Y, Yan D, Rao CY. Self-reported hand hygiene practices, and feasibility and acceptability of alcohol-based hand rubs among village healthcare workers in Inner Mongolia, China. J Hosp Infect. 2015;90(4):338-343. doi:10.1016/j.jhin.2015.04.006

13. O'Connor C, Casserly LF, Qazi J, et al. A case of fatal daptomycin-resistant, vancomycin-resistant enterococcal infective endocarditis in end-stage kidney disease. JMM Case Rep. 2015;2(5):e00089.

14. World Health Organization. Evidence of Hand Hygiene to Reduce Transmission and Infections by Multi-Drug Resistant Organisms in Health-Care Settings. WHO; 2014. 
15. Ministry of Health-Ethiopia. Health facility alcohol-based handrub preparation standard operation procedures. 2019. Available from: http://www.moh.gov.et/ejcc/am/health $\% 20$ facility $\% 20$ alcohol $\%$ 20based $\% 20$ hand $\% 20$ rub\%20preparation $\% 20$ standard $\% 20$ operating \%20procedure. Accessed June 12, 2020.

16. Alfahan A, Alhabib S, Abdulmajeed I, Rahman S, Bamuhair S. In the era of corona virus: health care professionals' knowledge, attitudes, and practice of hand hygiene in Saudi primary care centers: a crosssectional study. J Community Hosp Intern Med Perspect. 2016;6 (4):32151. doi:10.3402/jchimp.v6.32151

17. Larson E, Girard R, Pessoa-Silva CL, Boyce J, Donaldson L, Pittet D. Skin reactions related to hand hygiene and selection of hand hygiene products. Am J Infect Control. 2006;34(10):627-635. doi:10.1016/j.ajic.2006.05.289

18. Cure L, Van Enk R. Effect of hand sanitizer location on hand hygiene compliance. Am J Infect Control. 2015;43(9):917-921. doi:10.1016/j. ajic.2015.05.013

19. Sheong LC, Sin CK, Ahmad KB. Hand Hygiene Practice Among Pharmacy Staffs in Miri General Hospital. Sarawak J Pharm. 2016:102-112.

20. Ariyaratne M, Gunasekara T, Weerasekara M, Kottahachchi J, Kudavidanage B, Fernando S Knowledge, attitudes and practices of hand hygiene among final year medical and nursing students at the University of Sri Jayewardenepura. 2015.

21. Modi PD, Kumar P, Solanki R, Modi J, Chandramani S, Gill N. Hand hygiene practices among Indian medical undergraduates: a questionnaire-based survey. Cureus. 2017;9(7).
22. Traore O, Hugonnet S, Lübbe J, Griffiths W, Pittet D. Liquid versus gel handrub formulation: a prospective intervention study. Crit Care. 2007;11(3):R52. doi:10.1186/cc5906

23. Hernandes SED, ACd M, Sant'Ana JJ, et al. The effectiveness of alcohol gel and other hand-cleansing agents against important nosocomial pathogens. Braz J Microbiol. 2004;35(1-2):33-39. doi:10.1590/S1517-83822004000100005

24. Ministry of Health-Ethiopia. FMOH - National guideline for compounding of dermatological preparations 1st Edition. 2020. Available from: http:/www.moh.gov.et/ejcc/am/national_guideline_for_com pounding_dermatological_preparations. Accessed May 21, 2020.

25. Cole M. Exploring the hand hygiene competence of student nurses: a case of flawed self assessment. Nurse Educ Today. 2009;29 (4):380-388. doi:10.1016/j.nedt.2008.10.010

26. Jeong SY, Kim KM. Influencing factors on hand hygiene behavior of nursing students based on theory of planned behavior: a descriptive survey study. Nurse Educ Today. 2016;36:159-164. doi:10.1016/j. nedt.2015.09.014

27. Creedon SA. Healthcare workers' hand decontamination practices: compliance with recommended guidelines. J Adv Nurs. 2005;51 (3):208-216. doi:10.1111/j.1365-2648.2005.03490.x

28. Pittet D, Simon A, Hugonnet S, Pessoa-Silva CL, Sauvan V, Perneger TV. Hand hygiene among physicians: performance, beliefs, and perceptions. Ann Intern Med. 2004;141(1):1-8. doi:10.7326/ 0003-4819-141-1-200407060-00008
Drug, Healthcare and Patient Safety

\section{Publish your work in this journal}

Drug, Healthcare and Patient Safety is an international, peer-reviewed open-access journal exploring patient safety issues in the healthcare continuum from diagnostic and screening interventions through to treatment, drug therapy and surgery. The journal is characterized by the rapid reporting of reviews, original research, clinical, epidemiological and post-marketing surveillance studies, risk management, health

\section{Dovepress}

literacy and educational programs across all areas of healthcare delivery. The manuscript management system is completely online and includes a very quick and fair peer-review system. Visit http://www.dovepress.com/testimonials.php to read real quotes from published authors. 